\title{
The journey from self-exploration to self-identity: The evolution of contemporary Taiwanese graphic design
}

\author{
Li-Min Chen / National Kaohsiung Normal University / Kaohsiung / Taiwan
}

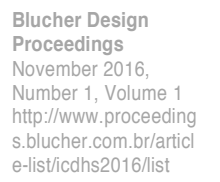

\begin{abstract}
To understand contemporary Taiwanese history of graphic design, one may want to learn the development of Taiwan politics first. This article will demonstrate how Taiwanese graphic design is influenced by political trends. However, when politics intervenes in graphic design, the creating process would be restrained since designers will need more thoughts before applying texts and images. The evolution of Taiwanese graphic design is the best testimony of the argument, by crossing the post-colonial period, the crisis of national- and ethnics-identity in 1971, and the social conflict after the end of Martial Law in1987. Graphic design works with Taiwanese consciousness may have less commercial sense, but describe the subjectivity value of the society with more accuracy. The works contain the essential elements that make graphic design step from localization to internalization which are the main streams in the history of Taiwanese contemporary design.
\end{abstract}

\section{Keywords}

Graphic design, subjectivity, martial law, Tai-Ke culture

\section{Introduction}

In 1949, after the defeat in the Chinese civil war, the government of the Republic of China, led by Chiang Kai-Shek and the Kuomintang (Chinese Nationalist Party) came to Taiwan. Henceforth, the practice of "Martial law" (1949-1987) followed. Meanwhile, due to the outbreak of Korean War in 1950, the Republic of China in Taiwan (R.O.C.) received financial support from the United States over the period 1951-1965. In 1954, the Sino-American Mutual Defense Treaty was agreed by the U.S. and R.O.C. government. Based on this interactive relationship, the States provided strong support for Taiwan in military, national defense and economy sectors. Consequently, influences from American culture and contemporary graphic design flowed in; one example being through pop music and album cover. Both American culture and the postcolonial culture after Japanese colonization offered Taiwanese graphic designers inspiration in the early phase. In 1971; the Senkaku Islands dispute, also known as the Diaoyu Islands dispute, compelled many Taiwanese to reflect upon their national- and, ethnic- identity. Thus, the trend of thinking was highlighted by this period's graphic design. It was not until the termination of Martial law that Taiwanese graphic designers had more freedom in their creations.

\section{The Aftermath effects of Post-colonialism (1945-1961)}

Taiwan was a Japanese colony from 1895 until the end of World War II. Although Taiwan no longer belonged to Japan, the connection remained. For example, the development of culture and art showed the huge impact of the culture assets and economic construction during the period under Japanese rule. These became the phenomena of the aftermath theory of Post-colonialism. The album cover design in this period exhibit influences from Japanese ruling and imported records (United Kingdom, United States, and China) as well. The style of Taiwanese design transformed from De Stijl, Art Nouveau, Victorian to Art Deco. In this period, the essence of culture is unclear; the subjectivity of Taiwan is absent. Also, most of the works present the same style as during the period as a Japanese colony, which demonstrates the argument that the relationship between "post-colonialism" and "colonialism" are connected instead of separated.

From 1961 to 1971, the economic growth had been focused on the export processing zone and trade surplus industries. The evolution of graphic design has entered the initial stage, due to the gradual stabilizing in political and economic sectors, leading to the rising need for living necessities. However, due to the lack of internation- 
al design information, Taiwanese graphic design had difficulty in joining the world trend. The notable graphic design contributions in this period are the first Taiwan graphic design exhibition; Black and White and Shi-Kuei Chien's album cover design for Happiness Records (Fig. 1).

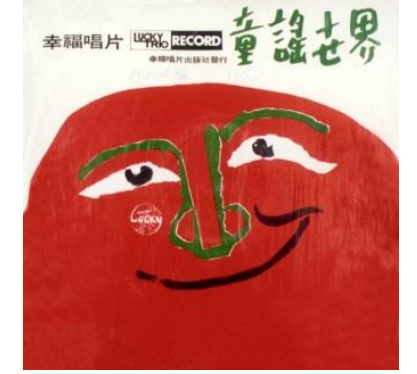

Fig. 1: Happiness Records designed by Shi-Kuei Chien in early 1960s

\section{During the late period of U.S. assistance to the time of exploring self-identity (1970-1987)}

The Senkaku Islands Dispute in 1971 triggered Taiwanese people's national and ethnicidentity. The incident led to local literature movement and development in art subjectivity. Graphic designers started to think about subjective consciousness in their works. Whether Taiwan is an extension of orthodox China or the nation China with subjectivity of Taiwan (R. O. C. in Taiwan) became a critical issue. 1971 was also the year the R.O. C. withdrew from the United Nations. After that, Taiwan faced the cruel reality of diplomacy difficulty. Moreover, the Senkaku Islands Dispute caused many Taiwanese to ponder over their nation's international position and ethnics-identity. These social incidents and ideological trend reflected on the poster design at that time. The graphic designers used various forms and elements to narrate different attitudes on subjectivity, such as traditional Chinese symbols versus local Taiwanese elements.

Under the atmosphere of the 1973 Oil Crisis, the Taiwanese government still pushed ahead with the Ten Major Construction Projects. The emphasis on economic construction demonstrated that the government confronted the reality that "Retake Mainland China" was not applicable at the moment. The Taiwanese government had expended most of the budget in national defense. In the 70s, the government reduced the budget for the military, and invested more money in economics, education, culture, and art construction. Even through the two oil crisis during the 70s, the shifting of the nation's financial allocation contributed to its economic growth and led to the rise of culture and art. Graphic design had gained its visibility, and became an efficient tool of product marketing, for instance, in poster design, Logo design (corporate identity system, visual identity), package design, advertising design, commercial photography, and public service advertising. Also, illustrations and design painting made huge progress in this era. Newspaper promoted the design combing illustration and layouts. Overall, in this period, graphic design's main purpose was commercial.

In 1971, the Taiwan Amoeba Design Association (TADA) was established. The intention of choosing the word "Amoeba" was for the pursuit of innocence, originality, the most fundamental principles of visual design, and designers with innovative ideas constantly brought up-to-date conception to art and society. (Lin,2003)

In 1972, Taiwan's first advertising magazine "Advertising Ages" was founded by Cheng-Feng Guo, which had immense influence on graphic design. With design magazine and exhibitions, graphic design was encouraged to present practicality and generality in society. In 1973, the first Taiwanese modern dance company "Cloud Gate" was founded. On December 10, 1979, the International Human Rights Day, one of the largest demonstrations throughout the Martial Law period occurred in Kaohsiung City, the "Formosa Incident." This incident changed the neglected attitude of the U. S. toward the practice of Martial Law in Taiwan. In addition, the Formosa Incident emphasized Taiwanese sovereignty and the value of democracy in people's minds. Near the end of the 70s, people became aware of the issue of national and ethnics identity.

\section{After Martial Law: the formation of subjective consciousness (1987-2000)}

\section{The calm before the storm}

A remarkable economic growth could be seen in Taiwan after the promotion of the Ten Major Construction Projects. Due to the prospective scene, graphic design was getting more and more attention, and the need from the market was greater than ever. Before 1987, when Martial Law was still in practice, the intention of graphic design was for practicality, illustrative and narrative purposes. Designers had to be careful in their use of texts and images. Messages that have critical or objectifying connotation intentionally or not were strictly forbidden. To meet the government's requirement thoroughly is a must for the creators at the time. In advertising, video, and communication industries, there were specific regulations which forbid violation of the national principle policy and only good manners and customs were allowed. Mass meetings, demonstrations, and the dissemination of unfavorable ideas about the government were forbidden as well. Rules which applied to society also applied to graphic design. Serving as a device for business 
marketing, there was not much freedom in design work. For example, the colour red was taboo, since it was the colour symbolizing communism, except for Chinese New Year and wedding occasions. In 1983, shortly after the opening of the Taipei Fine Arts Museum, the sculpture in front of the building-Tsai-Chien Lee's Finite to Infinite-faced the "red" issue. The art piece was a hefty geometric red sculpture, constructed by bending triangular columns to a similar symbol of "infinity." However, in 1985, because someone argued that the sculpture resembled a red star-a Communist symbol-the art work had to change the colour to silver. This kind of political intervention in art and design under the ideology of white terror had its origin in 1950, when the beginning of the Korean War prompted the ruling party in Taiwan to consolidate its regime. Due to the reason of corporates within the United States being against Communism, a series of white terror and anti-spy measures were implemented by the Taiwanese ruling party since 1950. Literature, movies, music, to fine art were all affected. It was not hard to imagine that the artists and designers had to comply with the Martial Law, set themselves in restricted creating environment, so that they could stay away

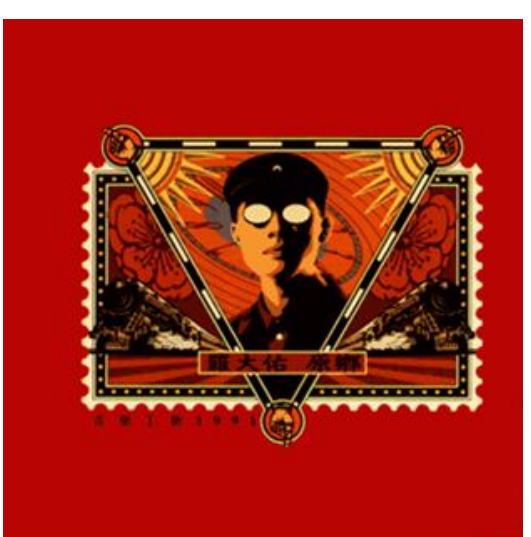

Fig. 2: Hometown, Da-yu Lo Design by Akibo Lee, 1991 from prison.

\section{Vintage nostalgia and the post-modern period in Taiwan (1990-1993)}

After the end of the Chinese Civil War in 1949, about 1.2 million soldiers and civilians left their homes in China for Taiwan. In 1987, the Taiwanese Kuomintang government lifted the ban on visiting relatives in Mainland China. The veterans in Taiwan had lost contact with their hometown for 38 years since 1949. With the ban lifted, they could finally go back and reunite with their longlost families. In this occasion, the sharp contrast of the two sides of the strait was exposed to the people. On the cover of Taiwanese singer and songwriter Da-yu Lo's album Hometown (1991) (Fig. 2), which was designed by Akibo Lee (1961-), one can see the confused and lost expression of the veteran after visiting his hometown in Mainland China. This album cover design is more like a stamp design, yet there is no postmark, date, nation, nor currency

value on it. With exchange between China, Taiwan, and Hong Kong, bans such as visiting relatives in mainland China were lifted, and the mail and phone calls between China and Taiwan became possible if transferring via an intermediary such as Hong Kong. Although the long-lost connection was reconnecting, the inner world of the people were disconnected separated by opposite sides (the two sides in the stamp). It is also a representation of the tragedy: innocent youth were deprived of the warmth of family life, due to conflicts and inappropriate conscriptions. They were forced to leave their home, parents, wives or beloved ones, even children. After so many years, they became alone, old and with sadness.

The design of the Hometown album cover wisely describes the complex and ambiguous feelings of Taiwan's new residents (the first generation of mainlanders) after their visit to their hometown. Time flies, and people change. The man in this cover wears a pair of white glasses. The oval shapes of the white glasses resemble "eggs", which in Chinese pronunciation has the homonym of "birth." This probably narrates the thoughts of those

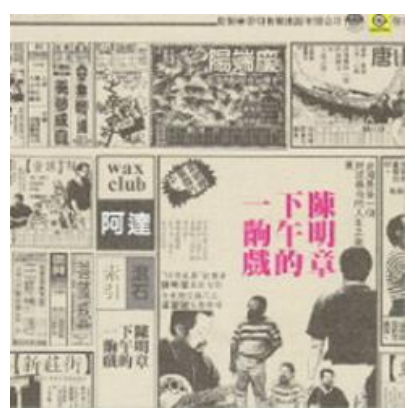

Figure 1 Fig. 3: Afternoon Theater, Ming-Chang Chen, 1990 "mainlanders" who retreated from mainland China to Taiwan: Where is the hometown? In the early 1990s, following the trend of internationalized business patterns, Taiwanese industries gradually shifted their investment to China to form globalized marketing operations. The trend of globalizing impacted considerably in the field of graphic design. In addition, the waves of "Taiwanese consciousness" and "local identity" were rising at the time. Local Taiwanese culture, dialect, art, and traditional opera have been degraded, due to a government who implemented policies since 1972, such as the designation of Mandarin as the official language and carrying out the civil Mandarin movement (traditional Chinese). It was until the 1990s that the government and people started to consider the importance of "Taiwanese consciousness." Thus, localized themes and materials begun to show up in graphic design.

On the album cover of Afternoon Theater (Fig. 3) by Taiwanese-dialect singer-

songwriter Ming-Chang Chen, the designer used classified ads in newspapers as the background of the cover, and smartly put the crew list into various ads. The classified ads were the epitome of economic development and the livelihood of Taiwanese society. After lifting the press ban in 1987, freedom of speech was no longer a political taboo or burden. Newspapers can even serve as the advertising device for propaganda and anti-propaganda purposes. In this piece of graphic design work, newspaper classified ads are used as the source material, which compared the once degraded local culture, dialect, and traditional opera, to the recruitment, lost-and-found, legal statement, etc. in the 
newspaper, things that belong to daily life. Graphic design is a visual culture that combines people's needs and the significance of time.

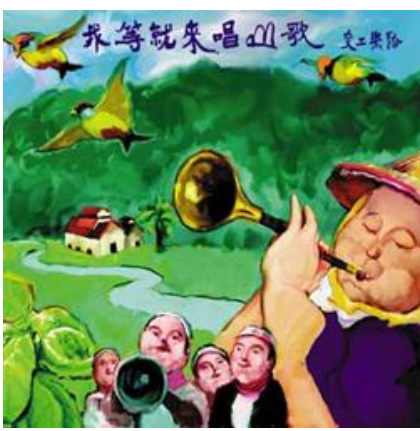

Fig. 4: Let Us Sing Mountain Songs, Labor Exchange Band, 1999

\section{Voices of social movements and the disadvantaged (1992-2000)}

In 1995 and 1997, China undertook two military exercises targeting Taiwan. The actions were attempts to intimidate and affect the first Taiwanese presidential election in 1996. Nevertheless, similar to the Senkaku Islands Dispute in 1971, the threat ran counter to China's desire. Taiwanese people started to reflect on the subjectivity of Taiwanese politics according to their political- and national-identity. Graphic designers actively responded to the calling. Their works presenting labor movements, the environmental topic, and the gay issue.

In 1999, the Labor Exchange Band published their debut album Let Us Sing Mountain Songs (Fig. 4). In the album title, the band used the traditional Taiwanese Hakka dialects word, "us" (wo-deng, 我等) instead of the Chinese "us" (wo-men, 我們). On the album cover, the designer utilized the hand-drawing illustration as the main expression. The illustration narrates the Mei-Nong Hakka people's lives, how they settled down on this very land, and how they built their home and established their career. The image presented a peaceful scene: the local people's unsophisticated faces, beautiful mountains and river, men and animals living together in harmony. The people and the land are united dependably in a simple style. On the right of the cover, the Hakka people blew the suona horn, a traditional instrument for gathering everyone. The insects and birds in the woods, as well as the fish in the river, together with human beings all summon up to sing the hometown's mountain songs. The mountain songs of the hometown were a kind of mother-tongue call, which is calling them from deep inside their hearts. The deeper meaning in this rustic and simple Mei-Nong Hakka village is the feeble cry from the local people calling for the public and government's attention. They look at the sky helplessly. They hope that humans could reflect on their indifference and brutality, and stop thinking and treating the land and other beings only from the point of view of economic benefit.

Touch (Fig. 5), is the first gay and lesbian record in the Chinese world. It is also the starting point of the combination between graphic design and the gay issue. "Touch" is an erotic characteristic of physical intimacy. It is also a private behavior of comforting. Sexual passion and pleasant sensations could be conveyed to others via touching. In this album cover, the overall impression is a sketch by charcoal pencil, presenting a spiritual body which is oppressed, unhappy and in unspeakable pain. The unmodified hidden lines express an unpleasant experience. The closed eyes and mouth, as well as the bended facial muscles, are like the inner world of gay people: they are unable to vent their feelings but remain in silence. The Chinese title "Touch" is composed by Mandarin Phonetic Symbols, which makes one associate the word with the incoherent speech of babies. It discloses the immature environment for discussing gay issue in Taiwan at the moment. There was still a long way to learn and grow, to realize a deeper understanding about gay people. On the side label, the designer highlighted the by inserting in word "gay". It implied the marginalization of gay people in the mainstream society. They were not very likely to be accepted by the majority. Moreover, there was no singer's name on the album cover, just like the "he" or "she" who was restrained and oppressed still not willing to "come out."

Taiwanese subjectivity and local consciousness on the international stage (2000-)

"Tai-Ke Culture" (or Tike culture) is a discriminated derogatory noun. "Tai-ke" was originally used by Taiwanese mainlanders to call Taiwanese local people with negative connotation. Nevertheless, in the end of 1990s, "Tai-Ke Culture" moved from the border to the core, became a popular trend in graphic design. Since 1990s, design exhibitions have been hold frequently among Taiwan, Hong Kong, and China. "Taiwan Image" became the source material for evolving from Taiwan consciousness and localization to the internationalization. After 2000, "Tai-Ke Style" is the highlight in graphic design, such as works by Akibo Lee, Qing-Yang Xiao (1966- ), Tzi-Chin Huang, and Jung-Yu Liao. These graphic designers share the common ground that they have designed both album cover and book binding. Another trend, the "Taiwan Image," is presented by fusing Taiwanese with Oriental elements in a postmodern way with simplicity. The design style develops from Chinese characters, idioms, and Taiwanese slang, such as works by Apex Pang-Soong Lin, Ming-Long Yo, and Hung-Tze Lin.

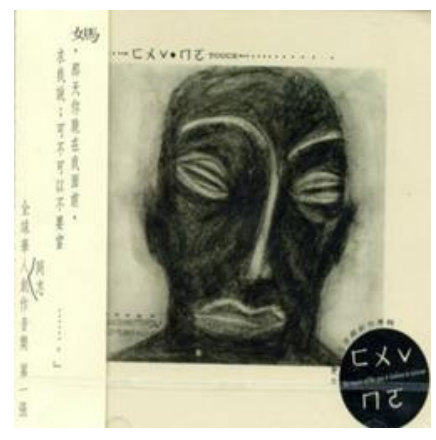

Fig. 5: Touch, Haine Record, 1998 


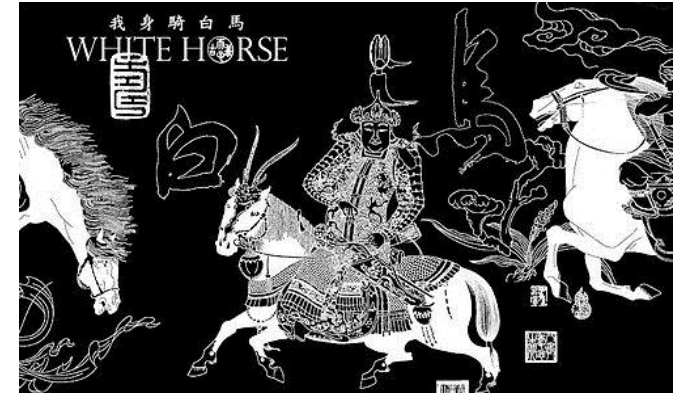

Fig. 6: Riding the White Horse, Qing-Yang Xiao, 2008
In 2005, the album cover of Monte Wang's The Wandering Accordion, designed by Qing-Yang Xiao, was nominated for Best Recording Package of the $47^{\text {th }}$ Grammy Awards. In 2008, Xiao got another nomination by the $50^{\text {th }}$ Grammy Awards with the album Riding the White Horse. The design style is the fusing of classic and modern. Xiao combines Taiwanese traditional opera (歌仔戲, kua-a-hi, a kind of song drama) with stone rubbing art. In the cover, an ancient general is riding a white horse (Fig, 6). The subjectivity of the white horse is highlighted by the ink color of stone rubbing. The graceful and aesthetic lines coordinate with the characters by ancient callig-

raphy and seal cutting, presenting a noble and elegant oriental flavor. This piece of work is a conceptual design containing both local taste and innovate fashion sense.

In March 18, 2014, thousands of students were surrounding and occupying Taiwan Legislative Yuan because the legislators were attempted to expedite a service pack with China. Graphic designer Aaron Nieh (1977- ) designed a whole page ad, Democracy at 4am, for New York Times. Nieh used a picture of blackness at 4 am to describe the incident that Taiwanese ruling party ordered police to suppress and evacuate the sit-in protest students. Another designer, Tzi-Chin Huang, made a series of "Tai-Ke Style" graphic design with Dada irony, photomontage collage, and Soviet Constructivism techniques to support the student movement. Compare to previous graphic design, which aimed to serve for economics and commercial, the design after 1987 became the praxis of social movement. It not only deepens the essence of graphic design also expands the application of the subject matters.

\section{Conclusion}

In Detachment and Unification: A Chinese Graphic Design History in Greater China Since 1979 (Wong, 2001), the author argued that it was after the end of Martial Law period that Taiwanese graphic design started has the autonomous to create, and the mature development can happen. In this article, the development of Taiwanese contemporary design is reviewed in three phases. The interactive creation between graphic design and social context could be possible only when political freedom is completed. Works with originality, subjectivity or deeper meaning will not exit, if a nation has excellent economy foundation but lack of freedom of thought and speech. The evolution of Taiwanese graphic design is the best testimony of the argument, by crossing the post-colonial period, the crisis of national- and ethnics-identity in 1971, and the social conflict after the end of Martial Law in1987. Graphic design works with Taiwanese consciousness may have less commercial sense, but describe the subjectivity value of the society with more accuracy. The works contain the essential elements that make graphic design step from localization to internalization which are the main streams in the history of Taiwanese contemporary design.

\section{References}

Chen, Li-Min. (2008) The Praxis of Social Context in Taiwanese Graphic Design from 1953-2000, Taipei: Song-Gerg.

Lin, Pin-chang. (2003) The Transition of Visual Communication Design in Taiwan from 1895-1990, Taipei: Quan Hau Technology.

Meggs, Philips B. (1999.) A History of Graphic Design. 4th Ed, New Jersey:John Wiiley \&Son,Inc.

Mizoeff , N. (1999.) What Is Visual Culture?, London: Routeledge.

Wong, Wendy S. (2001) "Detachment and Unification: A Chinese Graphic Design History in Greater China Since 1979," Design Issues, pp. 51-71.

Walker, John A. and Chaplin, Sarah. (1997) Manchester University Press, Visual Culture : An introduction. Walker, John A. (1990) Design History and the History of Design, London: Pluto Press.

\section{Biographical note}

Li-Min Chen completed his PhD in Design Studies at National Yunlin University of Science and Technology, Taiwan and has been teaching there since 1992. From 2004, he is in the Department of Visual Design at National Kaohsiung Normal University (NKNU) and is currently the Professor and Chairman of Department of Visual Design, NKNU. 